\title{
ALGUNAS MANERAS DE ENTENDER A LA NEUTRALIDAD
}

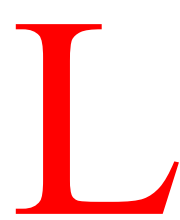

a idea de que el liberalismo se sustenta en la neutralidad, o que el liberalismo lleva la neutralidad a la práctica cuando funciona como sistema de gobierno, parece ser usualmente aceptada. O, para decirlo de un modo todavía menos controvertido: se acepta comúnmente que existe una vinculación cercana entre el liberalismo y la neutralidad (como también se acepta comúnmente que existe una vinculación cercana entre el libertarianismo y la neutralidad). Pero si se quiere concretar algo esta afirmación tan vaga el acuerdo ya no es fácil de alcanzar. No hay una concepción única de la neutralidad ni tampoco una posicion compartida por todos respecto al papel que la neutralidad debe desempeñar en el estado liberal (o en el estado libertario).

La neutralidad se identifica con una determinada actitud que debe adoptarse frente a ciertos planes de vida (y, entonces, frente a ciertos valores). Pero cuál sea esa actitud es algo debatible y quiero mostrar las diferentes posiciones que se han adoptado al respecto.

\section{Los rasgos de la neutralidad}

Indicar los rasgos principales de la neutralidad es una tarea que requiere varias etapas. Primero, por lo tanto, proporcionaré una visión general de la neutralidad y luego me ocuparé de las diferentes variantes que ella puede asumir.

\section{a) La idea de neutralidad}

Examinemos por un momento la manera en que Ackerman entiende a la neutralidad. Ninguna razón es una buena razón si 
ella requiere que aquel que tiene el poder asevere: a) que su concepción del bien es mejor que la que sostiene cualquiera de sus conciudadanos, o b) que, independientemente de su concepción del bien, él es intrínsecamente mejor que uno o varios de sus conciudadanos. Lo que esta concepción tiene de malo es que identifica de un modo estricto a la neutralidad con el diálogo. Pero nada impide abandonar el recurso del diálogo y retener el resto de las afirmaciones de Ackerman. Ser neutral, entonces, significa obrar de modo tal de no beneficiar a ninguna concepción del bien ni a ningún individuo en virtud de su presunta superioridad intrínseca ${ }^{1}$.

Esta idea suele ser compartida por los autores que se han ocupado del tema. Brian Barry $^{2}$, por ejemplo, dice que la política pública no debe basarse en la evaluación de las diferentes concepciones del bien que detentan los individuos. Raz ${ }^{3}$ identifica a la neutralidad con la idea antiperfeccionista de que la implementación y la promoción de los ideales de la vida buena no son materia legítima de acción gubernamental. La acción del Gobierno debe ser neutral respecto de los ideales de la vida buena. Y Larmore ${ }^{4}$ sostiene que el estado no debería buscar la promoción de ninguna concepción particular de la vida buena debido a su presunta superioridad intrínseca.

Sea que se hable de «concepciones del bien» o de la «vida buena» todos los autores que he citado están diciendo lo mismo: dentro de ciertos límites, el estado neutral no debe ni perjudicar ni beneficiar la concreción de los planes de vida de los ciudadanos. En realidad la exigencia es más fuerte: el estado neutral no sólo debe serlo respecto de la concreción de los planes de vida sino que también debe serlo respecto de su elaboración. Porque si el estado promueve una política educativa tal que los ciudadanos terminen condicionados a aceptar un solo plan de vida, no puede decirse que ese estado sea neutral simplemente porque luego no ayuda a concretarlo ni obstaculiza su concreción ${ }^{5}$.

${ }^{1}$ Cfr. Bruce Ackerman, Social Justice in the Liberal State, New Haven, Yale University Press, 1980, pág. 11 y Bruce Ackerman, «Why Dialogue?», The Journal of Philosophy, vol. 86, número 1, págs. 5-6 y 10-11.

${ }^{2}$ Brian Barry, «How Not to Defend Liberal Institutions», en R. Bruce Douglass, Gerald M. Mara y Henry S. Richardson (eds.), Liberalism and the Good, New York, Routledge, 1990.

${ }^{3}$ Joseph Raz, The Morality of Freedom, Oxford, Clarendon Press, 1986, pág. 110.

${ }^{4}$ Larmore, cit., pág. 43.

${ }^{5}$ Claro que el problema no es tan sencillo como lo acabo de plantear. Porque si el estado promueve una política educativa tal que habilite a los ciudadanos a elegir 
Hasta ahora sabemos sólo respecto de qué debe ser neutral el estado: respecto de los planes de vida de sus ciudadanos. Ni siquiera acerca de este punto -sin embargo- puede decirse que el tema se haya agotado. Ante todo, hay límites respecto de los planes de vida admisibles, como luego veremos. Y surge también el problema de si la neutralidad abarca a los planes de vida posibles o a los realmente sustentados. La idea resulta así muy incompleta, por lo que el paso siguiente consiste en averiguar cómo debe ser neutral el estado.

\section{b) Tipos de neutralidad}

Galston ${ }^{6}$ distingue cuatro tipos de neutralidad: 1) la neutralidad de oportunidad: un estado es neutral si es lo suficientemente amplio como para permitir que existan todos los tipos de vida; 2) la neutralidad de resultado: un estado es neutral sólo si el accionar de sus características principales, instituciones y políticas, no tiene una tendencia a favorecer ciertos tipos de vida y a obstaculizar otros; 3) la neutralidad de propósitos: las políticas del estado no deben esforzarse en promover ningún tipo de vida por sobre otro, y 4) la neutralidad de procedimientos: las políticas del estado deben justificarse sin apelar a la aparente superioridad intrínseca de ninguna concepción particular de la vida buena.

La primer variante presenta un problema obvio y es que -de hecho- ningún estado es neutral en esta acepción. Cualquier estado excluye ciertos tipos de vida (los que causan daño a terceros que no consienten en ello, por ejemplo). La segunda variante también resulta problemática puesto que es imposible que el accionar del estado no obstaculice ciertos tipos de vida. Nadie puede ser un mártir religioso en un estado que practica la libertad de cultos, como la practica el estado liberal, por ejemplo. Coincido con la tercer variante, por supuesto, desde que ella

entre varios planes de vida puede terminar destruyendo varios de esos planes. Estoy pensando en el efecto que una educación liberal tendría por ejemplo en los hijos de los adeptos a la secta Amish. Ese tipo de educación podría terminar produciendo lo que Michael McDonald llama la «hegemonía de la cultura liberal» [En «Liberalism, Community, and Culture», University of Toronto Law Journal, 42 (1992), pág. 127] En Wisconsin vs. Yoder (406 U.S. 205) la Corte Suprema de los Estados Unidos concedió la razón a varios miembros de la secta Amish que se negaron a que sus hijos asistieran a la escuela hasta los dieciseis años, una vez que éstos hubieron completado su octavo grado.

${ }^{6}$ Galston, cit., págs. 100-101. 
recoge la idea de la neutralidad que expuse en el apartado anterior. Si la tercer variante es la adoptada, la cuarta es innecesaria. En efecto: si el estado no promueve ningún plan de vida por sobre otro es obvio que no necesitará recurrir a la superioridad intrínseca de un plan de vida para justificar sus políticas. Creo entonces que la tercer variante de Galston recoge la idea central de la neutralidad ${ }^{7}$.

Raz, por su parte, distingue tres tipos de neutralidad política, de los cuales interesan dos de ellos: 1) la neutralidad restringida dice que no puede emprenderse ninguna acción política si ella establece una diferencia en la probabilidad de que una persona adopte una concepción del bien u otra, o de que ella lleve a cabo su concepción del bien, salvo que se realicen también otras acciones que cancelen esos efectos, y 2) la neutralidad abarcadora dice que una de las metas principales de la autoridad gubernamental, léxicamente prioritaria a cualquier otra, es asegurar para todas las personas una capacidad igual para perseguir en sus vidas y promover en su sociedad cualquier ideal del bien que sea de su elección ${ }^{8}$.

Lo que dice en síntesis la neutralidad restringida es que el estado es neutral cuando no hace nada, cuando contempla indiferente a todos los ciudadanos mientras ellos persiguen, con distinto éxito, sus planes de vida. Ésta es la manera más adecuada de entender a este tipo de neutralidad, porque la otra alternativa contemplada en la definición parece irracional: el estado dedica la misma cantidad de recursos para promover y para impedir la realización de los planes de vida de sus ciudadanos. Dedica $\$ 10.000$, por ejemplo, a promover los conciertos, y $\$ 10.000$ a impedir la realización de conciertos. Este despilfarro merece sin duda el calificativo de irracional. Puesto que el estado no hace nada en este caso me parece adecuado rebautizar a esta alternativa denominándola neutralidad negativa.

${ }^{7}$ Podría sostenerse que aunque se aceptara la tercer variante de Galston todavía la cuarta podría ser necesaria, puesto que un estado podría apelar a presuntas superioridades intrínsecas de planes de vida, no ya para promover alguno de ellos (posibilidad que la tercer variante prohíbe) pero sí para no permitir alguno de ellos (lo que la primer variante excluye) o para favorecer a otros (lo que la segunda variante veda). En el caso de la prohibición de algunos planes de vida ya he dicho que ella es inevitable en todo estado. Todo lo que la cuarta variante podría lograr es modificar los fundamentos de la prohibición: en lugar de mencionarse alguna presunta superioridad o inferioridad intrínseca la prohibición debería fundarse en el principio del daño. En el caso del favorecimiento, creo que la tercer variante, adecuadamente interpretada, no permite que esto ocurra, puesto que al no haber ningún plan de vida que se promueve no hay supuestos en los que deba recurrirse a la superioridad intrínseca.

${ }^{8}$ Raz, cit., pág. 115. 
Lo que dice la segunda alternativa, a su vez, es que el estado tiene que actuar, de modo tal que todos los ciudadanos tengan iguales perspectivas de llevar adelante sus planes de vida. Nótese que no estoy diciendo que el estado debe actuar igualmente respecto de todos sus ciudadanos, porque si lo hiciera las probabilidades de alcanzar un determinado plan de vida no se alterarían significativamente (podrían alterarse algo en virtud del principio de la utilidad marginal decreciente). Lo que digo es que en esta alternativa el estado debe tratar desigualmente a sus ciudadanos, de modo que -después de la actuación del estadotodos ellos tengan iguales probabilidades de llevar a cabo su plan de vida. Puesto que el estado actúa en este caso me parece adecuado rebautizar a esta alternativa denominándola neutralidad positiva.

\section{c) La neutralidad libertaria y la neutralidad liberal}

Hasta ahora he estado considerando conjuntamente a la neutralidad liberal y a la libertaria. Sin embargo, la distinción entre neutralidad negativa y neutralidad positiva ayuda a comprender en qué medida diferente son neutrales el estado libertario y el estado liberal. Ante todo hay que corregir la creencia de Ackerman ${ }^{9}$ de que los libertarios no defienden la neutralidad. Es muy claro que Nozick sostiene la existencia de un estado neutral y que se preocupa explícitamente de rebatir ciertas críticas relativas a la presunta falta de neutralidad del estado mínimo ${ }^{10}$. Lo que ocurre es que la idea «de neutralidad que utiliza el libertario no es la idea de neutralidad que utiliza el liberal».

El libertario concibe a la neutralidad como neutralidad negativa. El estado libertario acepta, por ejemplo, la distribución actual de la propiedad y respeta el status quo. El estado es neutral por omisión. La idea de neutralidad negativa se asocia fácilmente con la idea de libertad negativa: lo que promueve la neutralidad libertaria es la libertad negativa de los ciudadanos. Esta promoción de la libertad negativa es lo que justifica la existencia del estado libertario, puesto que desde el punto de vista de la libertad positiva da lo mismo que exista un estado libertario o que no haya ningún estado. El estado libertario confía en el mercado

372.

${ }^{9}$ Bruce A. Ackerman, «What is Neutral about Neutrality?», Ethics, Vol. 93, número 2, pág.

${ }^{10}$ Robert Nozick, Anarchy, State, and Utopia, Oxford, Basil Blackwell, 1974, págs. 271-273. 
para que se satisfagan los planes de vida de sus ciudadanos. Sin embargo, es difícil concebir al mercado como un instrumento neutral puesto que el mercado sólo toma en cuenta las preferencias de aquellos individuos que tienen recursos suficientes como para convertirlas en demanda.

El liberal concibe a la neutralidad como neutralidad positiva. El estado liberal no acepta como intocable la distribución actual de los recursos. Su neutralidad se manifiesta en la circunstancia de que todos sus ciudadanos tienen la misma probabilidad de llevar a cabo su plan de vida, y esto exige -en alguna medida- la redistribución de los recursos. La idea de neutralidad positiva se asocia con la idea de libertad positiva: lo que promueve la neutralidad liberal es la libertad positiva de los ciudadanos. El estado liberal, entonces, no está obligado a respetar el status quo (y a veces está obligado a no respetarlo). Un liberal puede aceptar que el mercado es un instrumento apto para satisfacer los planes de vida de los ciudadanos, pero se asegurará previamente que todos los ciudadanos pueden convertir sus preferencias en demanda, por contar con recursos suficientes.

En contra de la neutralidad libertaria puede argumentarse que un estado que acepta como dada una distribución muy desigual de recursos no es neutral respecto de sus ciudadanos, puesto que sabe que muy pocos de ellos podrán llevar a cabo sus planes de vida. En contra de la neutralidad liberal, a su vez, puede argumentarse que el liberalismo -por acción- perjudica los planes de vida de algunos individuos para mejorar los planes de vida de otros. La medida en que estas objeciones resulten convincentes dependerá del punto de vista que se adopte frente a la distinción entre el omitir y el actuar ${ }^{11}$. La crítica al libertarianismo es adecuada si no se acepta la distinción tajante entre el omitir y el actuar: al omitir, el estado libertario puede causar un daño. La crítica al liberalismo es adecuada si se acepta la distinción entre el omitir y el actuar: el estado no causa daño a nadie si omite, pero el estado liberal daña a algunos por acción.

El papel del estado libertario en lo que se refiere a la neutralidad es mucho más sencillo que el papel del estado liberal: el estado libertario no hace nada por nadie en materia de planes de vida, limitándose a proporcionarles la libertad negativa necesaria para llevarlos a cabo. (No es poco, se me dirá, pero ciertamente nadie creería que la libertad negativa es condición suficiente

${ }^{11}$ También podría depender de la actitud que se adopte en la controversia entre teorías que prohíben toda negociación en aras de maximizar un bien (deontologismo) y teorías que permiten tales negociaciones. 
para la realización de un plan de vida). Pero el liberal debe tratar de que todos los planes de vida tengan probabilidades de éxito y el esto produce algunas complicaciones.

El primer problema, planteado por Jones, es el de determinar los planes de vida que deben ser apoyados: ¿se trata de todos los planes de vida posibles o sólo de los realmente sustentados? ${ }^{12}$. Creo que el problema es más sencillo de lo que Jones piensa. El estado liberal no promueve planes de vida. Esto es: no es una institución que ofrezca planes de vida y proponga medios para llevarlos a cabo. Lo que hace el estado liberal es otra cosa: ayuda a sus ciudadanos a que los planes de vida que ellos han concebido puedan ser llevados a cabo. De modo que -como es obvio- los únicos planes de vida promovidos son los planes de vida realmente sustentados.

Claro está que esto no concluye con los problemas, desde luego. Ante todo, queda pendiente el saber por qué determinados planes de vida (y sólo esos planes) son los realmente detentados por los ciudadanos. ¿Hay algún defecto, acaso, en la educación liberal, que se concentra en algunos planes de vida y excluye otros de la consideración de los jóvenes? Como he dicho antes, la educación liberal debe ayudar a la formación de los planes de vida de un modo neutral, esto es, presentando el mayor menú de opciones posibles.

Otro problema pendiente es el de decidir la manera como el estado liberal promueve los planes de vida de los ciudadanos. Supongamos que el estado otorga un subsidio de $\$ 10.000$ para el ballet y otro subsidio de $\$ 10.000$ para conciertos de rock. ¿Obró el estado de manera neutral? No se puede saberlo, desde luego, hasta averiguar el número de individuos adictos a uno y a otro espectáculo, la situación económica de los adictos y la medida en que los $\$ 10.000$ contribuyen a que esa actividad se lleve a cabo. Esto dificulta enormemente la tarea del estado liberal (el estado libertario no tiene este problema porque sólo se abstiene de interferir en los planes de vida de sus ciudadanos). Una manera de resolver el problema consiste en abstenerse de apoyar al ballet y al rock. El estado liberal debe proceder de otra manera. Su propósito es la redistribución de los recursos, si esta es necesaria para que todos los ciudadanos disfruten de un grado de libertad positiva tal que pueda permitirles llevar a cabo -en cierta medida- sus planes de vida. El estado debería asignar recursos a los individuos y los individuos gastarlos en la persecución de

${ }^{12}$ Peter Jones, «The ideal of the neutral state», en Liberal Neutrality, cit., pág. 14. 
sus planes de vida. El estado -en cambio- no debería financiar ni el ballet ni el rock. Los individuos, con los recursos que el estado liberal les garantiza, podrían comprar a su gusto entradas para el ballet o para el rock.

\section{Los límites de la neutralidad}

Pero el liberal y el libertario, por igual, enfrentan ahora la misma dificultad, y esta es la de determinar cuales son los límites de la neutralidad. ¿Hasta dónde debe garantizar el estado libertario la libertad negativa de sus ciudadanos? ¿Cuáles son los planes de vida que el estado liberal debe aceptar que se lleven a cabo?

\section{a) Lo que la neutralidad no debe permitir}

En ambos casos la respuesta es la misma: el principio del daño a un tercero, que Mill enunció en On Liberty, marca el límite de la neutralidad. Hay varias maneras de arribar a las conclusiones que extrajo Mill. Una de ellas es a partir de la idea de privacidad, como lo hace por ejemplo Ruth Gavison. La sociedad deseable es una sociedad en la cual los individuos pueden crecer, mantener su autonomía y su salud mental, crear y mantener relaciones humanas y llevar vidas significativas. Algún grado de privacidad es necesario para capacitar al individuo para realizar estas cosas, y la privacidad -a la vez- indica la existencia de una sociedad pluralista y tolerante y contribuye a ella ${ }^{13}$. Justamente es la aplicación del principio milliano lo que garantiza la existencia de una esfera de privacidad. Otra manera posible de arribar al principio del daño es tomando la idea de Raphae ${ }^{14}$ de que el límite de la tolerancia está dado por la violación de un derecho. Aunque Raphael cree que su propuesta difiere de la milliana respecto de su alcance, lo cierto es que una forma adecuada de interpretar que se ha violado un derecho es afirmar que se ha dañado a otro. En el caso del libertarianismo creo que la invocación del principio del daño es explícita. Una de las pocas tareas del estado mínimo de Nozick es la seguridad interior, esto es, impedir que los ciudadanos sean dañados.

${ }^{13}$ Ruth Gavison, «Privacy and the limits of law», en Ferdinand D. Schoeman (ed.), Philosophical Dimensions of Privacy, Cambridge University Press, 1984, pág. 369.

${ }^{14}$ D. D. Raphael, «The Intolerable», en Susan Mendus (ed.), Justifying Toleration, Cambridge University Press, 1988. 
Por cierto que el principio del daño es un principio vago, y este descubrimiento no es actual, sino que se remonta a los contemporáneos del propio Mill. Hay casos claramente comprendidos dentro del principio, casos que el principio claramente no abarca, y casos dudosos. Si el límite de la neutralidad está dado por el principio del daño, y el principio del daño es vago, no hay más remedio que concluir que el límite de la neutralidad es vago (como son vagos, real o potencialmente, los límites de todos los conceptos empíricos). De todos modos creo que se ha exagerado la vaguedad que afecta al principio del daño. Raz, por ejemplo ${ }^{15}$ cree que ciertas acepciones de la neutralidad obligarían a compensar a los violadores en potencia por la prohibición de violar, puesto que esta sería una prohibición no neutral (puesto que discriminaría entre violadores y no violadores). Creo que se trata de un error. Todas las concepciones de la neutralidad -liberales o libertarías- encuentran su límite en el principio del daño. De modo que las conductas que dañan a un tercero están excluidas de la agenda de la neutralidad. Por eso cuando plantea el ejemplo del violador potencial claramente Nozick ${ }^{16}$ descarta la pretensión de que se lo compense calificándola de absurda. No se afecta la neutralidad cuando la conducta en cuestión viola el principio del daño: la neutralidad juega solamente dentro de los límites del principio milliano. Estos límites, a su vez, no dependen de la distinción entre el omitir y el actuar. Si una persona pasa al lado de otra que se está ahogando y, pudiendo salvarla sin riesgo, no lo hace, omite algo, pero esa omisión es intolerable de acuerdo al principio milliano. En cambio, si una persona toma activa participación para que un homosexual no ingrese en un club privado, claramente actúa en vez de omitir, pero esa conducta -como enseguida veremos- debe ser tolerada.

\section{b) Lo que la neutralidad debe permitir}

Si el límite de la neutralidad está dado por el principio del daño esto indica que el estado liberal y el estado libertario deben tolerar una gran variedad de planes de vida, más incluso de los que a primera vista podría parecer. Por ejemplo, a los intolerantes les es debido un grado mayor de tolerancia del que usualmente podría imaginarse. Supongamos que algunos individuos consideran que la heterosexualidad tiene un gran valor y asignan

\footnotetext{
${ }^{15}$ Raz, cit., pág. 115 .

${ }^{16}$ Nozick, cit., págs. 272-273.
} 
-consecuentemente- un gran disvalor a la homosexualidad. Como resultado ellos quieren segregar a los homosexuales. ¿Permite la neutralidad esta actitud? Hasta cierto punto sí. Pero, ¿cuál es ese punto? Desde luego que en una sociedad que aplica el principio de neutralidad no puede permitirse una discriminación pública de los homosexuales. No puede permitirse, por ejemplo, que se los discrimine en la administración del país, o en el ejército. Pero, como dice Larmore $^{17}$ la neutralidad como ideal político gobierna las relaciones públicas entre las personas y el estado y no las relaciones privadas entre las personas y las otras instituciones. De manera que si esos individuos que tanto valoran la heterosexualidad fundan un club privado, que no recibe fondos del estado, en donde se prohíbe el ingreso de homosexuales, la neutralidad exige que se permita la existencia de este club.

Es muy claro entonces que la neutralidad no permite que se lleven a cabo todos los planes de vida (ni siquiera excluyendo de la consideración los casos del daño a un tercero). Un intolerante que desee vivir en una sociedad en la que los homosexuales no puedan desempeñar cargos públicos no puede darse ese gusto. Y hay casos más complicados. En principio, pareciera que la neutralidad conduce a la tolerancia religiosa y a la libertad de cultos, lo que permite el desarrollo -en este aspecto- de todos los planes de vida. Nada más lejos de ello. Galston ${ }^{18}$ cita un trabajo inédito de un teólogo llamado Jon Gunneman que explica las objeciones de éste al estado liberal. Gunneman considera a este estado como ilegítimo en la medida en que el estado insiste en considerar a sus creencias como preferencias individuales y no como pretensiones de verdades públicas acerca del mundo, verdades públicas profundamente enraizadas en una tradición social que limita todas las otras pretensiones de autoridad. ¿Qué es lo que quiere Gunneman? Quiere algo más que la simple posibilidad de decir que él es cristiano y de practicar su culto. Quiere que todos coincidamos con él en la verdad de sus pretensiones y ese plan de vida no puede llevarlo a cabo en un estado neutral. Las preferencias externas de Gunneman no priman sobre las preferencias personales de los no cristianos ${ }^{19}$.

Pero entonces puede decirse que el estado liberal y el estado libertario no son realmente neutrales, puesto que favorecen la

${ }^{17}$ Larmore, cit., pág. 45.

${ }^{18}$ Galston, cit., pág. 11.

${ }^{19}$ La redacción de este párrafo no debe inducir a pensar que yo identifico las preferencias y los deseos, por una parte, y los planes de vida, por la otra. 
realización de ciertos planes de vida, precisamente la realización de los planes de vida de los individuos liberales, en un caso, y libertarios, en el otro. Ésta es la crítica que Nagel formula a la teoría de Rawls y que podría generalizarse para cualquier estado liberal, por ejemplo. Nagel observa que el modelo rawlsiano contiene un fuerte prejuicio individualista. La posición originaria parece presuponer una teoría neutral del bien y una concepción liberal individualista de acuerdo a la cual lo mejor que puede desearse a cualquiera es la persecución sin obstáculos de su propio camino siempre que no se interfiera con los derechos de los demás. Nagel piensa que entre estos planes de vida la construcción de Rawls es neutral, pero que no lo es respecto de aquellas concepciones del bien que no se ajustan al modelo individualista ${ }^{20}$.

Una forma de responder a esta crítica ${ }^{21}$ es mostrar que el liberalismo no permite la persecución irrestricta de los planes de vida liberales. Es cierto que el grupo de intolerantes que deseaba que los homosexuales no desempeñaran cargos públicos no puede darse ese gusto en una sociedad liberal, pero el liberal que desea vivir en una sociedad donde no existan clubs privados que discriminen a los homosexuales tampoco puede darse ese gusto en una sociedad liberal. Dentro de los límites impuestos por el principio del daño muchos planes de vida distintos pueden surgir bajo el liberalismo y bajo el libertarianismo, en una forma parecida a la utopía que Nozick diseña en la parte final de su libro.

De todos modos, y como hemos visto más arriba, parece imposible evitar algún grado de prejuicio en favor de las políticas liberales o libertarias cuando ellas se ponen en práctica. Como dice Charles Taylor cuando se establece una estructura dada el teórico también establece la gama de políticas posibles. Establecer una estructura restringe la variedad de posturas que pueden ser justificablemente adoptadas ${ }^{22}$. Vuelvo al ejemplo de la secta Amish que mencioné en la nota $* * * 5$. Es muy difícil que siga siendo posible para un individuo el adoptar el plan de vida de los Amish si previamente el individuo en cuestión ha sido educado bajo un régimen liberal. La estructura liberal parece

${ }^{20}$ Thomas Nagel, «Rawls on Justice», en Norman Daniels (ed.), Reading Rawls, Oxford, Basil Blackwell, 1975, págs. 9-10.

${ }^{21}$ Como crítica al liberalismo. Como crítica a Rawls creo que él la acepta a partir de los presupuestos que aparecen en «Justice as Fairness: Political not Methaphysical», Philosophy and Public Affairs, Vol. 14, número 3.

${ }^{22}$ Charles Taylor, «Neutrality in Political Science», en Peter Laslett y W. G. Runciman (eds.), Philosophy, Politics and Society, third series, Oxford, Basil Blackwell, 1978, págs. 55-57. 
imposibilitar ${ }^{23}$ la subsistencia de la cultura Amish, así como la cultura Amish requiere que se deje de lado el ideal liberal de la autonomía, donde el individuo, posee un amplio menú de opciones.

\section{La justificación de la neutralidad}

Hasta ahora me he comportado de un modo neutral respecto de la neutralidad. No la he elogiado ni la he criticado, ni mucho menos me he inclinado por la versión liberal o por la versión libertaria de la neutralidad. Ha llegado el momento, entonces, de pronunciarse sobre los méritos de la neutralidad analizando las distintas estrategias justificatorias de la misma.

Las que abundan, por otra parte. Una de ellas reside en resaltar el valor de la autonomía. Si el plan de vida del individuo debe ser autónomamente elegido y no impuesto desde afuera, esta circunstancia obliga a la abstención del gobierno en relación a los posibles planes de vida. En otras palabras: el respeto de la autonomía del individuo conduce a la neutralidad de los gobiernos ${ }^{24}$. Otra estrategia consiste en negar que existan valores absolutos, en negar incluso el valor absoluto de la autonomía. Esta posición escéptica sostiene que sólo puede haber opiniones acerca de los buenos planes de vida, pero que no puede probarse que ningún plan sea intrínsecamente superior a otro. Si ningún plan de vida es objetivamente mejor que otro el gobierno debe ser neutral respecto de todos ellos. Una tercera estrategia afirma el valor de la experimentación acerca de los planes de vida como medio de mejorar a los individuos. Y no son estas, desde luego, las únicas estrategias posibles.

Voy a concentrarme en lo que sigue en otras dos alternativas: la que sostiene que la neutralidad es un valor y la que le niega tal carácter. Para poder optar entre ellas voy a recurrir a algunos ejemplos y aquí alteraré en cierta medida el carácter de la exposición que he seguido hasta ahora. En efecto: hasta aquí me he ocupado por igual de la neutralidad liberal y de la libertaria. En lo que sigue -y por una cuestión de claridad expositivaconcentraré los ejemplos en la neutralidad liberal. Confío, sin embargo, que la conclusión a la que arribo se aplique también a la neutralidad libertaria.

${ }^{23}$ La imposibilidad no es de iure -por supuesto-, sino de facto.

${ }^{24}$ No comparto esta estrategia, sin embargo, porque creo que el liberalismo de la neutralidad debe separarse claramente del liberalismo de la autonomía. 


\section{a) La neutralidad como valor}

Hay muchos autores (como Ackerman y Barry, por ejemplo) que piensan que la neutralidad es un valor. Aunque no lo dicen expresamente supongo que están pensando que es un valor objetivo. Waldron ${ }^{25}$ es más explícito y afirma que la neutralidad es un valor objetivo: si el escepticismo fuera verdadero los propios súbditos no tendrían motivo para preferir un plan de vida por sobre otro. Los tres autores coincidirían entonces con la manera en que Dworkin encara el problema. El liberalismo, cree Dworkin, no puede basarse en el escepticismo. Su moral constitutiva ordena que los seres humanos sean tratados como iguales por su gobierno, no porque en moral política no exista lo correcto o lo incorrecto, sino porque esto es lo que es correcto ${ }^{26}$.

Aquí comienzan los problemas, sin embargo. La neutralidad no tiene por qué ser el único valor que se acepte, por supuesto. En otras palabras: es posible que el liberalismo sea una teoría pluralista y no una teoría monista. Pero si la teoría es pluralista sin duda se le exigirá que sea consistente, de modo que si la neutralidad figura como un valor (aunque no como el único valor) esto significa que el sistema no puede contener valores contrarios a la neutralidad.

Aceptemos entonces que la neutralidad es un valor objetivo. ¿A quién está dirigida la norma moral que recoge este valor objetivo? Hasta ahora he supuesto, sin decirlo expresamente, que la neutralidad estaba dirigida al estado, o, para emplear una expresión más concreta, que estaba dirigida al legislador. Pero imaginemos por un momento que la norma en cuestión está dirigida al ciudadano, que es el ciudadano el que debe actuar neutralmente.

¿Qué tiene que hacer ahora el ciudadano? Ante todo, adviértase que estamos pasando aquí de la ética axiológica ( $x$ es valioso) a la ética normativa (se debe hacer $x$ ) pero el paso no es complicado. La ética axiológica dice en este caso que la neutralidad es valiosa. La ética normativa, a su vez, dice que se debe hacer lo valioso y evitar lo disvalioso. Si este concepto de ética normativa se complementa con la concepción neutralista, se concluye que se debe hacer aquello que promueva la neutralidad y evitar aquello que la impida. Esto es lo que debe hacer el ciudadano ${ }^{27}$.

\footnotetext{
${ }^{25}$ Waldron, cit., págs. 72 y 73.

${ }^{26}$ Ronald Dworkin, A Matter of Principle, Cambridge, Mass., Harvard University Press,
} 1985, pág. 203.

${ }^{27}$ Aquí podría distinguirse entre dos variantes: a) una ética normativa que fuera neutral 
Pero, ¿qué quiere decir esto? ¿Quiere decir que el ciudadano tiene que ser neutral respecto de todos los demás valores? Esta exigencia sería ridícula, puesto que entonces el ciudadano no podría elegir ninguna plan de vida. Como dice Waldron ${ }^{28}$ es absurdo sugerir que la neutralidad respecto de lo que hace a la vida digna de ser vivida es una buena cosa. Porque si el concepto de la vida buena tiene un uso entonces no puede exigirse la neutralidad a todos, porque «bueno» es en sí mismo un concepto evaluativo, discriminatorio.

En realidad la situación es todavía más complicada para nuestro infortunado ciudadano. Por una parte él debe ser neutral respecto de todos los planes de vida, pero ciertamente no puede ser neutral respecto de los planes de vida que impidan, o perjudiquen, la neutralidad. Debe evitar que esos planes se lleven a cabo puesto que así se lo exige su ética normativa ${ }^{29}$.

Una posible solución consistiría en decir que el individuo en cuestión debe contemplar imparcialmente los planes de vida de todos los demás individuos en la medida en que esos planes no conspiren contra la neutralidad, y que él mismo debe elegir un plan de vida que no atente contra la neutralidad. Pero esta solución tiene un inconveniente: si la neutralidad es un valor los únicos planes de vida aceptables -como hemos visto- son los planes de vida neutrales, esto es, los planes de vida compatibles con el liberalismo. Lo único que se puede hacer en una sociedad neutral es ser liberal. Esto es peor todavía de lo que imaginaba Nagel. No es que exista un prejuicio en favor del liberalismo: es que sólo se puede ser liberal.

¿Y es malo que en una sociedad sólo se pueda ser liberal? Puede serlo. Ante todo, desaparece cualquier tolerancia respecto del intolerante. El club de heterosexuales al que antes me refería no puede ser permitido, puesto que atenta contra la neutralidad. Pero si se tolera un solo plan de vida -el plan de vida liberal- ¿en qué medida puede decirse que esa sociedad valora las distintas concepciones del bien. Si la neutralidad concebida como un valor objetivo impone la adopción de un único plan de vida -el plan de vida liberal- ¿en qué sentido ese estado es neutral? Si la

y consecuencialista, esto es, que prescriba acciones que promueven la neutralidad, incluso mediante la realización de algunas acciones que fueran ellas mismas no neutrales, y b) una ética normativa que fuera neutral y deontológica, esto es, que prescriba acciones neutrales, incluso aquellas que atienten contra la neutralidad general futura.

${ }^{28}$ Waldron, cit., pág. 70.

${ }^{29}$ Esto es así, obviamente, sólo para el neutralista consecuencialista que mencioné en la nota 39. 
neutralidad se entiende como un valor objetivo termina prohibiendo todos los planes de vida que sean contrarios -siquiera en mínimo grado- a la neutralidad. Llamo a esto la paradoja de la neutralidad. Es una paradoja en la medida en que ser neutral respecto de los planes de vida no debería consistir en aceptar sólo los planes de vida que son neutrales ${ }^{30}$.

Pero, podría replicarse, estas dificultades son sólo consecuencia de haber ubicado a la neutralidad donde no corresponde hacerlo ${ }^{31}$. En el estado liberal no interesa la neutralidad de los ciudadanos sino la neutralidad del legislador, puesto que lo que le importa al estado liberal es la formación y la concreción de los diversos planes de vida, y en estos aspectos la influencia del legislador es incomparablemente mayor que la de los ciudadanos. Si el legislador considera a la neutralidad como un valor objetivo no se produce por eso solo la paradoja de la neutralidad, continúa la réplica. El legislador valora la neutralidad respecto de su tarea. Él es neutral respecto de los planes de vida de los ciudadanos, sean estos planes de vida neutrales o no. El legislador permite el funcionamiento del club de heterosexuales porque este plan de vida no viola el principio del daño y el legislador es neutral respecto de todos los planes de vida de los ciudadanos que no violen el principio del daño.

Acepto que si la neutralidad se entiende como dirigida al legislador desaparece la paradoja de la neutralidad. Y acepto también que la manera más simple de entender a la neutralidad en el estado liberal es considerar que ella se dirige al legislador. Pero en este caso, con toda claridad, el valor objetivo se vuelve

${ }^{30}$ Una manera de cuestionar la paradoja consiste en distinguir entre la neutralidad evaluativa y la neutralidad en la acción. La primera se entiende como la neutralidad que se ejercita al valorar igualmente a todos los planes de vida de los ciudadanos. La segunda se entiende como la que se ejercita al no interferir con los diferentes planes de vida de los ciudadanos. En este caso la paradoja se disipa si se exige sólo a los ciudadanos una neutralidad en la acción, aunque él valore de manera diferente los distintos planes de vida. Pero, ¿se disipa realmente la paradoja con este argumento? No lo creo así y vuelvo por un momento a la distinción entre ética axiológica y ética normativa que mencioné más arriba. Si la ética normativa nos dice que debemos hacer $x$ y alguien pregunta el por qué, la respuesta sólo puede residir en apelar a la ética axiológica: porque $x$ es bueno, o es valioso. De otro modo, ¿qué quiere decir que se debe hacer $x$ ? De la misma manera, si se debe actuar neutralmente, esto significa que la neutralidad es valiosa. Y si la neutralidad es valiosa para el ciudadano, la paradoja reaparece.

${ }^{31}$ Y podría ser así. Supongamos que la neutralidad comparta con el igualitarismo la característica de ser un bien de segundo orden. Del hecho de aceptar al igualitarismo como valioso no se seguiría que el único plan de vida de los individuos debería consistir en perseguirlo. Lo mismo podría suceder con la neutralidad. 
intolerablemente ad hoc. Ahora se dice que la neutralidad es objetivamente buena, pero -curiosamente- sólo al nivel del legislador ${ }^{32}$. Al nivel de los ciudadanos la neutralidad ya no cuenta como valor objetivo, porque si contara, el legislador estaría obligado a no ser neutral respecto de los planes de vida de los ciudadanos, sino a preferir los planes de vida neutrales. La ética normativa del legislador le dice que está obligado a ser neutral en su papel de legislador, pero que la neutralidad no es obligatoria a nivel de los ciudadanos. La neutralidad es una virtud extraña, entonces, pues sólo opera después de un cierto nivel. Es posible que alguien quiera defender a la neutralidad -y, así, al liberalismo- sobre la base de un valor de este tipo. Pero la defensa queda expuesta a este comentario: - «iQué afortunada coincidencia que exista un valor que precisamente obligue a realizar la conducta que usted intenta defender!».

Creo que justificar la neutralidad sobre la base de un valor objetivo -incluso si pudiera demostrarse la existencia de valores de ese tipo- presenta más problemas de los que resuelve. Por eso me parece adecuado proponer otra estrategia para la justificación de la neutralidad, de la que me ocuparé en el apartado siguiente.

\section{b) La neutralidad como meta-valor}

Ensayemos entonces una justificación escéptica, que es una de las tantas que consideraba Ackerman ${ }^{33}$ : mientras todos tienen una opinión acerca de la vida buena ninguno puede saber si esa concepción es superior a la de cualquier otro; cualquiera que afirme que él o sus propósitos son intrínsecamente superiores no sabe de qué está hablando. Y este tipo de afirmaciones son las que la neutralidad prohíbe, dice Ackerman. Debo reconocer que el tipo de justificación escéptica de la neutralidad suele estar desacreditado en la fílosofía contemporánea. Para tomar un solo ejemplo, Galston ${ }^{34}$ dice que la defensa del liberalismo basada en el escepticismo es fundamentalmente incorrecta, puesto que ninguna forma de vida política puede ser justificada

${ }^{32}$ Aunque se aceptara la idea expuesta en la nota anterior igualmente un aire de paradoja rodearía a este valor. Porque -comparando otra vez a la neutralidad con el igualitarismo- un legislador que valorara a la igualdad estaría obligado a frustrar a aquellos planes de vida de sus ciudadanos que condujeran a resultados no igualitarios.

${ }^{33}$ Ackerman, Social Justice in the Liberal Satate, cit., págs. 11-12.

${ }^{34}$ Galston, cit., págs. 79 y 80. 
sin algún punto de vista acerca de lo que es bueno para los individuos.

Sin embargo, voy a intentar -como he dicho- un argumento de este tipo. Supongamos que ningún plan de vida tenga un valor objetivo. Esto no significa, por supuesto, que los individuos sean indiferentes entre los distintos planes de vida que están a su alcance; que desaparezca la noción de valor objetivo no significa que desaparece también la noción de preferencia. Los individuos prefieren ciertos planes de vida a otros, y le asignan un valor al plan de vida que ellos prefieren.

La neutralidad obra como un meta-valor en este sentido: obra como un principio regulador de esos valores subjetivos. No es un valor, ni está en el mismo nivel que esos valores subjetivos. Nos dice en cambio cómo debemos tratar a esos valores. Nos dice que ninguno de esos valores es objetivo, y que no debemos tener preferencias por un valor respecto de otro sino permitir que se desarrollen por igual todos los planes de vida en la medida en que ellos sean compatibles. (Ya hemos visto como difieren el liberalismo y el libertarianismo en cuanto al desarrollo de los planes de vida, pero esta diferencia no interesa para mi propósito actual).

¿Qué consecuencias prácticas tiene esta actitud? La más importante, a mi juicio, es la de que el legislador debe aceptar ahora un cierto grado de intolerancia, en tanto no exceda los límites del principio del daño. En realidad, si la intolerancia no excede los límites del principio del daño el legislador debe ser neutral entre los planes de vida tolerantes y los intolerantes (desde luego que en la esfera privada, como ya hemos visto). El legislador debe aceptar la práctica de la homosexualidad entre adultos que consienten, pero también debe aceptar la existencia y funcionamiento del club de heterosexuales que antes mencionaba. El legislador que considera a la neutralidad como un metavalor es neutral respecto a esas dos actividades. La neutralidad considerada como meta-valor, entonces, permite ser realmente neutral ente los distintos planes de vida, donde la palabra «realmente» quiere decir que la balanza no se inclina hacia el lado de los planes de vida neutrales.

La idea de la neutralidad como un meta-valor ${ }^{35}$ es consistente, como se ve, con el escepticismo ético. El principio regulador de

\footnotetext{
${ }^{35}$ Alguien podría objetar que es incorrecto hablar de un meta-valor al mismo tiempo que se niega que existan valores objetivos. Prefiero utilizar el término -sin embargo- porque estoy presuponiendo todo el tiempo la existencia de valores subjetivos.
} 
los valores dice: como no hay valores objetivos, seremos neutrales respecto de los valores subjetivos. No es que la neutralidad sea intrínsecamente buena, en el sentido de que es intrínsecamente bueno que haya diversos planes de vida. Es que ningún plan de vida es intrínsecamente bueno, y por eso $^{36}$ se es neutral entre ellos. Mill creía que un gobierno neutral contribuía mejor al conocimiento de la verdad objetiva. Yo creo que el Gobierno debe $^{37}$ ser neutral porque no hay verdades objetivas en moral.

Que se acepte o no el argumento que he presentado depende entre otras cosas de la manera como se conciba al liberalismo. Si se cree que hay un tipo de vida caracterizado particularmente como liberal, probablemente el argumento será rechazado porque tolera planes de vida no liberales. Si se cree que el estado liberal es liberal precisamente porque no promueve un tipo específico de vida, probablemente el argumento será aceptado, porque conduce exactamente a ese resultado (aunque también podría coincidirse con la conclusión pero rechazarse mi argumento, lo que no me molestaría en absoluto en tanto se proporcionara un argumento mejor).

Pero para ser neutrales acerca de este argumento examinemos también lo que puede decirse en su contra. Si no existen valores objetivos, si los valores se equiparan de algún modo con las preferencias, entonces no hay ninguna garantía de que el legislador se comporte de un modo neutral. El legislador podría razonar de este modo: «Todos los valores son subjetivos, por lo que puedo elegir cualquiera de ellos que yo prefiera. Yo prefiero el modo de vida autoritario, de modo que me comportaré autoritariamente con los ciudadanos». Esta crítica es correcta si se la reduce a límites adecuados. Lo que la crítica dice con verdad es que no hay una vinculación lógica entre el subjetivismo axiológico y la adopción de la neutralidad como principio regulatorio metavalorativo. Pero no creo que nadie pretenda que existe una vinculación de ese tipo. Lo que se invoca es una probabilidad, conexión o correlación, de tipo sicológico: sabiendo que no hay valores objetivos, es probable que el legislador -al considerar que todos ellos pueden equipararse a la expresión de alguna preferencia- tienda sicológicamente a ser neutral entre tales valores,

${ }^{36} \mathrm{El}$ «por eso» no debe interpretarse como una conexión lógica.

${ }^{37} \mathrm{El}$ «debe» no hay que interpretarlo como afirmando un enunciado de la ética normativa, porque de lo contrario la afirmación sería inconsistente. En efecto: por una parte se diría que no hay enunciados normativos verdaderos y por la otra se diría que es verdadero el enunciado normativo de que se debe ser neutral. El «debe» en cuestión, en cambio, hay que interpretarlo dentro del contexto de la tesis que estoy sosteniendo, por lo que se ubica en el plano meta-valorativo. 
al no tener ninguna razón objetiva para preferir a uno por sobre otro.

¿Es esta probabilidad garantía suficiente de que el legislador se comportará de un modo neutral? No, desde luego. Pero, ¿cuál es la alternativa? Si deseamos que se nos garantice $^{38}$ que el legislador adoptará un punto de vista liberal necesitamos postular la existencia de un valor objetivo que posee dos características, que muchos encontrarían paradójicas si se las considera conjuntamente: a) la característica de considerar buena la neutralidad al nivel legislativo, y b) la característica de no considerarla buena al nivel de los ciudadanos. Si falta la característica: a) por supuesto que el legislador no tiene por qué comportarse de un modo neutral. Pero si falta la característica b) tampoco tiene por que hacerlo, puesto que si la neutralidad es buena a nivel del ciudadano, él no puede ser neutral respecto de los planes de vida no neutrales, sino que debe actuar prejuiciosamente (esto es, no-neutralmente) respecto de esos planes de vida.

Como se ve, ninguna de las dos justificaciones de la neutralidad está exenta de dificultades. Pero quiero concluir abandonando por un momento mi neutralidad y declarando mi preferencia por la alternativa que considera a la neutralidad como un metavalor ${ }^{39}$.

${ }^{38}$ Recurriendo a medios éticos, desde luego. Lo que de hecho haga un legislador puede muy bien no depender de la ética.

${ }^{39}$ Agradezco a Juan Rodríguez Larreta e Ignacio Zuberbuhler sus valiosas observaciones sobre este trabajo. 
